\title{
Characteristics of Mothers Who Have Children with Fetal Alcohol Syndrome or Some Characteristics of Fetal Alcohol Syndrome
}

\author{
Valborg L. Kvigne, MBA; Gary R. Leonardson, PhD; Joseph Borzelleca, MD, MPH; \\ Ellen Brock, MD, MPH; Martha Neff-Smith, PhD, MPH, RN; and \\ Thomas K. Welty, MD, MPH
}

Background: Health care providers can more effectively prevent fetal alcohol syndrome and prenatal alcohol exposure if they know more about mothers who have children with fetal alcohol syndrome (FAS) or some characteristics of FAS.

Methods: We conducted two retrospective case-control studies of Northern Plains Indian children with FAS and some characteristics of FAS diagnosed from 1981 to 1993 by using the International Classification of Diseases, Ninth Revision, Clinical Modification (ICD-9-CM), code 760.71. We compared mothers who had children with FAS or some characteristics of FAS with mothers who had children that did not have FAS.

Results: Compared with control mothers, 43 mothers who had children with FAS and 35 mothers who had children with some characteristics of FAS were older, had fewer prenatal visits, more pregnancies, more mental health problems, and more injuries (both total and alcohol-related). Although the prevalence of drinking was high in both case and control mothers, case mothers had more alcoholrelated medical problems, drank heavily, in binges, and daily more often than control mothers.

Conclusions: Women with injuries and mental health problems should be screened for substance use. Mothers of children with FAS or of some characteristics of FAS have numerous needs that must be addressed to prevent future prenatal alcohol exposure. (J Am Board Fam Pract 2003;16:296-303.)

Fetal alcohol syndrome (FAS) is the most common cause of preventable mental retardation in the United States. ${ }^{1}$ Although there are great intertribal and regional differences in alcohol use, abuse, and FAS among American Indians, overall rates of alcohol-related mortality exceed US all-races rates. ${ }^{2}$ Because surveillance for FAS has been sporadic and incomplete, national rates of FAS are not well established. The prevalence of FAS among Northern Plains Indians was estimated at 8.5 per 1,000 live births. $^{3}$ Alcohol use during pregnancy among Northern Plains Indian women was reported at

Submitted, revised, 11 February 2003.

From the Aberdeen Area Indian Health Service (VLK, TKW), Public Health Service Indian Hospital, Rapid City, SD; Mountain Plains Research (GRL), Bozeman, Mont; Virginia Commonwealth University (JB), (EB) Richmond; and Binghamton University (MNS), Binghamton, NY. Reprint requests should be addressed to Thomas K. Welty, MD, 5950 East Jeremy Lane, Flagstaff, AZ 86004.

This study was supported through a memorandum of agreement between the Indian Health Service and the Centers for Disease Control and Prevention. The opinions expressed in this article are those of the authors and do not necessarily reflect those of the Indian Health Service.
$56 \%$ in an urban site in a rural state. ${ }^{4}$ The purpose of this study was to describe Northern Plains Indian women who have children with FAS and women who have children with some characteristics of FAS, so that health care providers can provide optimal care for such women, determine which women are at risk for having children with FAS, and intervene to prevent FAS and prenatal alcohol exposure.

\section{Methods}

The protocol was reviewed and approved by the Aberdeen Area Indian Health Service (IHS), and the national IHS Institutional Review Boards, and four Northern Plains tribes. At four Northern Plains IHS hospitals or clinics, FAS or some characteristics of FAS were diagnosed in children from 1981 to 1993 by using the International Classification of Diseases, Ninth Revision, Clinical Modification (ICD-9-CM), code 760.71.5 This code includes noxious influences (specifically alcohol) affecting the fetus or newborn through placenta or breast milk and includes FAS. 
FAS cases were defined as children who met all five of the following criteria, based on documentation in their medical records: (1) prenatal alcohol exposure or maternal history of alcohol consumption, (2) FAS diagnosed or noted as a suspected diagnosis by a physician, (3) one or more facial features characteristic of FAS, (4) growth deficiency (height or weight $\leq 10$ th percentile for age), and (5) central nervous system impairment. ${ }^{6}$ If children met only one to four of these criteria, they were defined as cases having some characteristics of FAS.

Of 142 medical records in the four communities that had an ICD-9 code of 760.71, 43 (30\%) met 5 FAS case criteria. Of the remaining 99 medical records, 35 that met one to four FAS case criteria were randomly selected. Thus, we report two separate analyses of data: one based on 43 case mothers whose children had FAS compared with 86 control mothers (study 1), and the second based on 35 case mothers whose children had one to four characteristics of FAS compared with 70 different control mothers (study 2). The methods used for both studies were identical. For each case mother, we selected two control mothers from the same community: one who gave birth immediately before the birth of the child with FAS or the child with some characteristics of FAS, and one who gave birth immediately after. If the control child had FAS, the next nearest child born was selected instead.

For inclusion into the studies, medical records of the mother and child for both cases and controls had to be available for abstraction. When available, medical records of the following family members were also abstracted for both cases and controls: father of the index child, maternal grandmother, next older sibling, and next younger sibling.

Maternal alcohol abuse was defined when one or more of the following patterns of drinking were recorded in the maternal medical record: (1) heavy, which included terms "heavy," "intoxicated," "alcohol abuse," "drunk," and "alcoholism;" (2) binge drinking of five or more drinks per occasion or blood alcohol levels higher than $200 \mathrm{mg} / \mathrm{dL}$; or (3) daily alcohol use.

We reviewed the entire lifetime maternal medical record (hospital, emergency department, and outpatient) for documentation of sexual abuse, suicide attempts, depression, cirrhosis, delirium tremens, and maternal cognitive function. For aerosol use, sexually transmitted diseases, injuries (inten- tional and unintentional), smoking, and alcohol abuse, we limited our review to five years before the birth of the case or control child until 1 August 1995. We used data abstracted from those reviews to calculate and compare rates of these problems in case and control mothers. We defined maternal cognitive dysfunction as cognitive problems that differed from those caused by adult alcohol abuse but that are typical of adults who are affected by fetal alcohol exposure themselves (poor judgment, poor memory, slow learning, and lack of abstract thinking skills).

The primary author provided orientation for all abstractors and regularly monitored their work. Two abstractors reviewed the same medical records of $10 \%$ of the cases and controls. If there was less than $90 \%$ concurrence, the charts were abstracted again. There was $91.5 \%$ concurrence in double abstraction of 31 medical records. We double entered all data and corrected all discrepancies.

A matched analysis was done using corrected McNemar chi-square and correlated $t$ tests to determine statistical significance of differences in categorical and continuous variables. ${ }^{7,8}$ Using chi-square and $t$ tests to determine statistical significance, we analyzed unmatched case and control mothers who went to alcohol treatment or attempted suicide to compare relapse rates and numbers of suicide attempts. Fisher's exact test was used for discrete variables when there were fewer than five expected observations in one or more cells of a $2 \times 2$ table. $P$ values of .05 or less were considered to be statistically significant. We calculated odds ratios (OR) using maximum likelihood estimates and exact $95 \%$ confidence interval to assess the strength of associations. We used logistic regression to verify results controlling for age and to look for the best predictors for having a child with FAS.

\section{Results}

By definition, children of case mothers in study 1 had all five FAS criteria, and children of case mothers in study 2 case had an average of 3.2 FAS criteria. On average case mothers from both studies started prenatal care during the sixth month of pregnancy, compared with control mothers, case mothers had significantly fewer prenatal visits, had more pregnancies, had more children before the index child, and were older (Table 1). Three case mothers in study 1 and one case mother in study 2 
Table 1. Demographic and Pregnancy Factors of Mothers of Children with Fetal Alcohol Syndrome (FAS) (Study 1) and Mothers of Children with Some Characteristics of Fetal Alcohol Syndrome (Study 2).

\begin{tabular}{|c|c|c|c|c|c|c|}
\hline \multirow[b]{2}{*}{ Demographic and Pregnancy Factors } & \multicolumn{3}{|c|}{ Study 1} & \multicolumn{3}{|c|}{ Study 2} \\
\hline & $\begin{array}{c}\text { Case }^{*} \\
\mathrm{n}=43 \\
\text { Mean (Range) }\end{array}$ & $\begin{array}{c}\text { Control } \\
\mathrm{n}=86 \\
\text { Mean (Range) }\end{array}$ & $P$ Value & $\begin{array}{c}\text { Case* }^{*} \\
\mathrm{n}=35 \\
\text { Mean (Range) }\end{array}$ & $\begin{array}{c}\text { Control } \\
\mathrm{n}=70 \\
\text { Mean (Range) }\end{array}$ & $P$ Value \\
\hline Number of criteria for FAS & $5.0(5-5)$ & $0.48(0-3)$ & .001 & $3.2(1-4)$ & $0.31(0-3)$ & .001 \\
\hline Age (years) & $26.6(17-39)$ & $24.2(17-37)$ & .02 & $28.0(18-41)$ & $24.5(17-37)$ & .01 \\
\hline Education (years) & $9.8(8-12)$ & $11.0(8-16)$ & .003 & $10.2(7-12)$ & $11.0(6-15)$ & .11 \\
\hline Gravidity & $6.6(1-15)$ & $5.0(1-14)$ & .007 & $6.0(2-11)$ & $4.6(1-12)$ & .02 \\
\hline Number of live-born children & $5.5(1-12)$ & $4.3(1-12)$ & .01 & $5.5(2-11)$ & $4.1(1-10)$ & .01 \\
\hline Number of children before index child & $3.4(0-10)$ & $1.9(0-9)$ & .001 & $3.1(0-10)$ & $1.7(0-8)$ & .01 \\
\hline Number of children after index child & $1.2(0-6)$ & $1.3(0-4)$ & .65 & $1.4(0-7)$ & $1.5(0-4)$ & .96 \\
\hline Number of prenatal visits ${ }^{\dagger}$ & $3.7(0-14)$ & $6.4(0-17)$ & .004 & $3.1(0-9)$ & $7.0(0-20)$ & .001 \\
\hline Month of first prenatal visit ${ }^{\dagger}$ & $5.2(1-9)$ & $4.5(1-9)$ & .17 & $5.0(2-9)$ & $3.8(1-8)$ & .04 \\
\hline
\end{tabular}

${ }^{*}$ None of the differences between study 1 and 2 case mothers are statistically significant.

${ }^{\dagger}$ Data are for the pregnancy with the index child.

had died; none of the control mothers in either study had died.

Case mothers of children with FAS (study 1) were three times more likely to receive care for unintentional injuries $(\mathrm{OR}=3.00 ; 95 \% \mathrm{CI}, 1.16$, 7.99) and more than six times more likely to receive care for intentional injuries $(\mathrm{OR}=6.69 ; 95 \% \mathrm{CI}$, $2.58,17.88)$ than control mothers. Case mothers of children with some characteristics of FAS (study 2) were more likely to receive care for intentional injuries $(\mathrm{OR}=2.62,95 \% \mathrm{CI}, 1.16,5.96)$ than control mothers. Mean numbers of injury-related visits for unintentional injuries were also significantly higher for case mothers than control mothers in study 1 (Table 2). Among case mothers from both studies, about one third of the unintentional injuries and more than one half of the intentional injuries were alcohol-related.
Sexual abuse and mental health problems (primarily depression) were recorded significantly more frequently in medical records of case mothers of children with FAS than in records of control mothers (study 1) (Table 3). About $40 \%$ of case mothers from both studies had made at least one suicide attempt (Table 3). Although proportions of case and control mothers from both studies who ever made a suicide attempt did not differ significantly, mothers of children with FAS who had attempted suicide had a significantly higher mean number of attempts (3.2) than control mothers who had attempted suicide $(1.7)(P=.05)$.

Almost two-thirds of case and control mothers from both studies had a history of sexually transmitted diseases (most commonly chlamydial infection, gonorrhea, and trichomoniasis) recorded in their medical records, but rates did not differ sig-

Table 2. Mean Number of Visits for Maternal Injuries 5 Years Before the Birth of the Index Child (or Until 1, August 1995) for Mothers with Children with Fetal Alcohol Syndrome (Study 1) and Mothers of Children with Some Characteristics of Fetal Alcohol Syndrome (Study 2).

\begin{tabular}{|c|c|c|c|c|c|c|}
\hline \multirow[b]{2}{*}{ Injury Characteristics } & \multicolumn{3}{|c|}{ Study 1} & \multicolumn{3}{|c|}{ Study 2} \\
\hline & Case* & Control & $P$ Value & Case* $^{*}$ & Control & $P$ Value \\
\hline Unintentional injuries $^{\dagger}$ & 4.6 & 2.6 & .004 & 3.0 & 2.6 & .78 \\
\hline Alcohol involved $^{\dagger}$ & 1.7 & 0.2 & .003 & 1.2 & 0.5 & .14 \\
\hline Hospitalized & 0.9 & 0.2 & .05 & 0.9 & 0.2 & .15 \\
\hline Intentional injuries ${ }^{\dagger}$ & 4.6 & 2.0 & .06 & 3.3 & 1.8 & .05 \\
\hline Alcohol involved $^{\dagger}$ & 2.5 & 0.6 & .01 & 2.2 & 0.9 & .002 \\
\hline Hospitalized & 0.8 & 0.1 & .12 & 0.3 & 0.3 & .49 \\
\hline
\end{tabular}

*None of the differences between study 1 and 2 cases are statistically significant.

†The mean numbers of total injuries and total alcohol-related injuries were significantly higher for both study 1 and 2 case mothers than control mothers $(P=.01)$. 
Table 3. Medical Record Documentation of Maternal Sexual Abuse, Mental Health Problems, Sexually Transmitted Diseases, and Family Planning.

\begin{tabular}{|c|c|c|c|c|c|c|}
\hline \multirow[b]{2}{*}{ Characteristics } & \multicolumn{3}{|c|}{ Study 1} & \multicolumn{3}{|c|}{ Study 2} \\
\hline & $\begin{array}{l}\text { Case } \\
(\%)^{*}\end{array}$ & $\begin{array}{c}\text { Control } \\
(\%)\end{array}$ & $\begin{array}{l}\text { Odds Ratio } \\
\text { (95\% CL) }\end{array}$ & $\begin{array}{l}\text { Case } \\
(\%)^{*}\end{array}$ & $\begin{array}{c}\text { Control } \\
(\%)\end{array}$ & $\begin{array}{l}\text { Odds Ratio } \\
\text { (95\% CL) }\end{array}$ \\
\hline Sexual abuse & 25.6 & 8.1 & $2.33(1.04-5.36)$ & 17.1 & 10.0 & $1.80(0.47-6.87)$ \\
\hline Diagnosed coexisting mental health problem & 62.8 & 41.9 & $2.48(1.05-6.34)$ & 51.4 & 27.1 & $2.94(1.11-8.69)$ \\
\hline Diagnosed with depression & 34.9 & 17.4 & $2.38(1.00-6.06)$ & 20.0 & 15.7 & $1.37(0.39-4.83)$ \\
\hline Suicide attempts & 39.5 & 27.9 & $1.66(0.72-3.90)$ & 40.0 & 21.4 & $2.29(0.89-6.18)$ \\
\hline Had sexually transmitted disease & 69.8 & 68.6 & $1.07(0.41-2.87)$ & 62.9 & 57.1 & $1.26(0.51-3.20)$ \\
\hline $\begin{array}{l}\text { Use of family planning } \\
\text { Condoms } \\
\text { Birth control pills } \\
\text { Sterilization }\end{array}$ & $\begin{array}{l}58.1 \\
27.9 \\
16.3 \\
20.9\end{array}$ & $\begin{array}{r}60.5 \\
47.7 \\
32.6 \\
8.1\end{array}$ & $\begin{array}{l}0.91(0.40-2.07) \\
0.34(0.12-0.90) \\
0.37(0.11-1.00) \\
3.52(1.00-16.08)\end{array}$ & $\begin{array}{r}45.7 \\
20.0 \\
14.3 \\
5.7\end{array}$ & $\begin{array}{l}54.3 \\
21.4 \\
38.6 \\
11.4\end{array}$ & $\begin{array}{l}0.65(0.26-1.63) \\
0.90(0.25-3.24) \\
0.29(0.10-0.84) \\
0.50(0.11-2.35)\end{array}$ \\
\hline
\end{tabular}

Note: study 1 = mothers of children with fetal alcohol syndrome; study 2 = mothers of children with some characteristics of fetal alcohol syndrome.

*None of the differences between study 1 and study 2 case mothers are statistically significant.

$\mathrm{CI}=$ confidence interval.

nificantly between case and control mothers (Table 3). Although rates of family planning usage did not differ, case mothers of children with FAS were more likely than control mothers (study 1) to choose sterilization as a method of birth control and less likely to choose condoms (Table 3). Case mothers of children with some characteristics of FAS (study 2) were less likely than control mothers to be taking birth control pills.

About $80 \%$ of case mothers in study 1 and $60 \%$ of case mothers in study 2 had alcohol-related medical problems. Trauma, delirium tremens, and alcohol abuse were reported significantly more frequently for case mothers than control mothers of both studies (Table 4). Nine case mothers in study $1(23.0 \%)$ and 6 case mothers in study $2(15.4 \%)$ had all three categories of alcohol abuse (heavy, binge, and daily) recorded in their medical records, whereas none of the control mothers in study 1 and only one mother in study 2 had all three recorded ( $P<.05$ for both differences).

Significantly higher proportions of case mothers than control mothers from both studies were referred for alcohol treatment, and case mothers participated in treatment programs more frequently than control mothers (Table 4). Of the women referred for treatment, higher proportions of case mothers than control mothers from both studies continued to use alcohol after first treatment. Relapse rates decreased after their last treatment.

Because of their high alcohol content, aerosols, including Lysol and hairspray, are sometimes con- sumed as a beverage by persons with severe chemical dependency. In this study, none of the control mothers abused aerosols compared with $7.0 \%$ of case mothers in study 1 and $2.9 \%$ of case mothers in study 2 (Table 4). Smoking rates were high in case and control mothers in both studies and did not differ.

Case mothers from both studies had significantly higher rates of cognitive dysfunction typical of adults with FAS than did control mothers (Table 4). Alcohol use was documented significantly more often in the records of maternal grandmothers of case children in both studies compared with the records of grandmothers of control children. More than $50 \%$ of case and control fathers in both studies had alcohol use documented in their medical records.

Logistic regression analyses did not change the significance of the associations reported. Maternal drinking, maternal age, intentional injuries, depression, and sexual abuse were the strongest predictors of FAS. The only significant differences between case mothers in study 1 and study 2 are noted in Table 4 and suggest that mothers of children of FAS had significantly higher levels of alcohol consumption and a more serious alcohol addiction than mothers of children who had some characteristics of FAS.

\section{Discussion}

Because of difficulties in defining "some characteristics of FAS," research has been limited for moth- 
Table 4. Percentage of Mothers Who Had a Medical Record Documentation of Maternal Alcohol Abuse, Medical Problems, Treatment, Aerosol Abuse, Grandmother and Partner Alcohol Use.

\begin{tabular}{|c|c|c|c|c|c|c|}
\hline \multirow[b]{2}{*}{ Characteristic } & \multicolumn{3}{|c|}{ Study 1} & \multicolumn{3}{|c|}{ Study 2} \\
\hline & $\begin{array}{l}\text { Case } \\
(\%)\end{array}$ & $\begin{array}{l}\text { Control } \\
(\%)\end{array}$ & $\begin{array}{l}\text { Odds Ratio* or } \\
P \text { Value }\end{array}$ & $\begin{array}{l}\text { Case } \\
(\%)\end{array}$ & $\begin{array}{l}\text { Control } \\
(\%)\end{array}$ & $\begin{array}{l}\text { Odds Ratio* or } \\
P \text { Value }\end{array}$ \\
\hline $\begin{array}{l}\text { Alcohol-related medical problems } \\
\text { Cirrhosis } \\
\text { Trauma } \\
\text { Delirium tremens }\end{array}$ & $\begin{array}{l}81.4^{+} \\
16.3 \\
60.5 \\
25.6\end{array}$ & $\begin{array}{c}19.8 \\
0 \\
10.5 \\
0\end{array}$ & $\begin{array}{c}17.14(5.30-88.15) \\
P=.001 \\
14.43(4.36-75.13) \\
P=.001\end{array}$ & $\begin{array}{r}57.1^{\dagger} \\
2.9 \\
42.9 \\
11.4\end{array}$ & $\begin{array}{c}20.0 \\
0 \\
12.9 \\
1.4\end{array}$ & $\begin{array}{l}5.67(1.99-19.84) \\
\quad P=.72 \\
5.77(1.78-24.41) \\
8.0(0.79-393.98)\end{array}$ \\
\hline $\begin{array}{l}\text { Alcohol abuse at any time recorded in chart } \\
\text { Heavy } \\
\text { Binge } \\
\text { Daily }\end{array}$ & $\begin{array}{l}95.3^{\dagger} \\
93.0^{+} \\
41.9 \\
37.2\end{array}$ & $\begin{array}{r}39.5 \\
34.9 \\
14.0 \\
1.2\end{array}$ & $\begin{aligned} & 39.85(6.52-1638.3) \\
& 42.79(7.02-1756.8) \\
& 4.65(1.72-14.59) \\
& 48.77(6.98-2136.0)\end{aligned}$ & $\begin{array}{l}77.1^{\dagger} \\
57.1^{\dagger} \\
48.6 \\
28.6\end{array}$ & $\begin{array}{r}32.9 \\
21.4 \\
14.3 \\
1.4\end{array}$ & $\begin{array}{c}6.12(2.21-21.01) \\
5.40(1.88-18.96) \\
6.41(2.03-26.73) \\
20.0(2.85-867.95)\end{array}$ \\
\hline Referral to alcohol treatment & $79.1^{\dagger}$ & 25.6 & $13.80(4.21-71.49)$ & $57.1^{\dagger}$ & 11.4 & $8.58(2.83-34.57)$ \\
\hline Alcohol use following first treatment & 94.1 & 50.0 & $16.0(2.65-125.1)$ & 75.0 & 37.5 & $5.00(0.66-43.02)$ \\
\hline Alcohol use following last treatment & 50.0 & 22.7 & $3.40(0.86-13.59)$ & 40.0 & 0 & $P=.10$ \\
\hline Aerosol abuse & 7.0 & 0 & $P=.07$ & 2.9 & 0 & $P=.77$ \\
\hline Cigarette use & 62.8 & 60.5 & $1.10(0.49-2.51)$ & 62.9 & 54.3 & $1.43(0.57-3.56)$ \\
\hline $\begin{array}{l}\text { Maternal problems possibly related to prenatal } \\
\text { alcohol exposure }\end{array}$ & 30.2 & 10.5 & $3.83(1.35-10.86)$ & 17.1 & 2.9 & $6.00(1.07-60.79)$ \\
\hline Maternal grandmother alcohol use & 92.9 & 43.9 & $24.00(2.70-213.4)$ & 78.9 & 38.9 & $4.98(1.03-48.11)$ \\
\hline Partner's alcohol use & 62.8 & 55.8 & $1.32(0.63-2.74)$ & 65.7 & 54.3 & $1.50(0.69-3.27)$ \\
\hline
\end{tabular}

Note: study 1 = mothers of children with fetal alcohol syndrome; study 2 = mothers of children with some characteristics of fetal alcohol syndrome.

*95 percent confidence interval in parentheses.

${ }^{\dagger}$ Differences between study 1 and study 2 case mothers are statistically significant.

†Two case mothers of children with fetal alcohol syndrome had alcohol use documented only in the child's medical record.

ers whose children do not have all the criteria for FAS. In the past fetal alcohol effects was used as a diagnosis in these children; now the terms alcoholrelated neurodevelopmental disorder and alcoholrelated birth defects are used. ${ }^{9}$ These two studies of mothers of children who had FAS and some characteristics of FAS provide a unique opportunity to learn more about each group of women and to make comparisons between them. Case mothers from both studies had similar demographic characteristics and rates of injuries, but mothers of children with FAS (study 1) had significantly higher rates of alcohol abuse and referral for alcohol treatment than mothers with children with some characteristics of FAS (study 2). Thus, children of mothers in study 1 might have had greater prenatal alcohol exposure that caused them to have all five characteristics of FAS.

The mean age for mothers in study 1 was 26.6 years and for mothers in study 2 was 28.0 years compared with mean maternal ages of 26.7, 27.4, 29.0, 29.7 and 29.9 years in four studies of mothers of children with FAS. ${ }^{10-14}$ In fact, the first modern published report of advanced maternal age as a risk factor for FAS was also conducted among American
Indians. ${ }^{14}$ Another study found that pregnant women older than 35 years had the highest prevalence of prenatal drinking $(21.9 \%)$ of any agegroup. $^{15}$

Occurrence of FAS at a young maternal age in our study suggests an early age of onset of alcohol abuse, possibly related to high rates of alcohol use among maternal grandmothers. Women who abuse alcohol receive less support from their families and friends than do women who do not abuse alcohol. ${ }^{16}$ Younger women tend to drink in a heavy, episodic pattern. ${ }^{4,17}$ Because heavy alcohol use has a stronger association with FAS than moderate drinking, ${ }^{18}$ this heavy-binging pattern is likely to have more adverse effects on the fetus than consumption of smaller quantities of alcohol per occasion. ${ }^{19}$ In addition to binge drinking, case mothers in study 1 and study 2 were 49 and 20 times, respectively, more likely than control mothers to drink alcohol on a daily basis.

Gravidity and parity for case and control mothers in both studies were greater than reported for urban Northern Plains Indian prenatal patients. ${ }^{4}$ Mothers who have children with FAS or some characteristics of FAS should be strongly encour- 
aged to postpone pregnancies until they are able to abstain from alcohol use. Case and control mothers from both studies had similar rates of family planning usage, but a higher proportion of case mothers in study 1 chose sterilization. In some cases, however, sterilization was not readily available, and mothers often requested sterilization more than once before the procedure was completed. Case mothers in study 2 were less likely than control mothers to use birth control pills. Accessibility to all forms of family planning needs to be a priority.

The mean educational level of case mothers in study 1 (9.8 years) was significantly lower than that for control mothers (11.0 years), compared with a mean maternal educational level of 10.6 years for mothers of children with FAS in North Dakota. ${ }^{13}$ A study in Alaska found $41 \%$ of case mothers had not graduated from high school. ${ }^{12}$ Lower educational level has been associated with an earlier age of first drinking and with heavier alcohol use in American Indians. ${ }^{20}$ Educational materials need to be written at an appropriate reading level.

More then $60 \%$ of case and control mothers from both studies lived with partners who also drank alcohol, a pattern consistent with findings of other studies. ${ }^{4,10,17}$ Cohabitation with partners who drink alcohol is strongly associated with women's drinking. ${ }^{10,17}$

Women who use alcohol experience more physical and sexual abuse than women who do not drink alcohol. ${ }^{16}$ Women who experience such abuse are also more likely to have mental health problems. ${ }^{16,21}$ Problem drinking among women is linked to depression, ${ }^{22}$ and suicide occurs more frequently among young women who drink alcohol than among women who abstain from alcohol. ${ }^{23}$

Unintentional injuries were significantly more common among case mothers than among control mothers in study 1. Previous studies have shown that serious trauma is often associated with alcohol use. ${ }^{24,25}$ Intervening when women seek care for injuries related to alcohol use might prevent prenatal alcohol use as well as further injuries.

Case mothers from both studies had more medical problems related to their alcohol use than control mothers. In contrast with men, women who experience liver malfunction as a result of alcohol abuse might not recover when they quit drinking or cut down on their alcohol use. ${ }^{26}$ Despite their many problems, case mothers had only about one half the number of prenatal visits as control moth- ers, suggesting the need for active follow-up of prenatal patients when they miss their appointments.

Mothers of children with FAS are at greater risk for having more children with FAS. If mothers continue to drink with successive pregnancies, children born later often have more profound effects of FAS. ${ }^{9}$ To prevent this repetitive, worsening damage to subsequent children, all mothers of children with FAS and some characteristics of FAS should be referred to treatment for their alcohol abuse. Referrals to treatment occurred more frequently for case mothers than for control mothers in both studies, likely as a result of the severity of alcohol abuse in case mothers. To prevent FAS and other alcohol-related effects, it is essential to counsel women of child-bearing age preconceptually to avoid substance use during pregnancy and to advise residential treatment for women who continue to abuse alcohol.

Because of the immense difficulty of overcoming chemical abuse and dependency, treatment relapses are common regardless of type and duration of current treatment modalities. ${ }^{28}$ In our study, relapses after the first treatment occurred more often for case mothers than for control mothers who were referred to treatment in both studies. Alcohol use after the last treatment program decreased for both case and control mothers, showing that repetitive treatments are useful.

Women in treatment are often found to abuse other drugs as well. ${ }^{23}$ Although use of aerosols as a beverage has been described, ${ }^{29}$ use in pregnancy has not been reported. Women who drink products containing alcohol that are not beverages are likely so dependent on alcohol that they will drink any available liquid with a high alcohol content. Such potentially toxic products (eg, Lysol and hairspray) are readily available, and their consumption should be strongly discouraged. Smoking rates were similar for case and control mothers (60\%), indicating need for universal smoking-cessation programs for prenatal patients in this population.

More than $60 \%$ of case and control mothers from both studies had a history of sexually transmitted diseases. This finding suggests need for further education on prevention, for more rigorous case finding and treatment, and for counseling and testing for human immunodeficiency virus infection. 
Most case grandmothers in study 1 and 2 (93\% and $79 \%$, respectively) had alcohol use documented in their medical records compared with less than one half of control grandmothers. Although documentation of alcohol use during pregnancy was limited in the grandmothers' charts, there were indications that nearly one third of case mothers themselves had cognitive dysfunction suggestive of adult FAS. Similar familial patterns of heavy drinking reported in a study of FAS in South Africa ${ }^{10}$ raise questions of whether fetal susceptibility to alcohol has a genetic basis, or whether it simply relates to familial patterns of alcohol abuse that are environmentally determined.

There are several limitations to these studies. The small numbers of case mothers in both studies limited the power of both studies to detect differences. Although the IHS unified medical record, which includes inpatient, outpatient, and emergency department records, enabled us to link risk factors and outcomes for most case and control mothers, the studies were limited by the inability to interview mothers or examine children. One important variable we could not fully evaluate was the cause of maternal cognitive dysfunction. Was it a result of fetal alcohol exposure or was it due to other causes? Ascertaining the cause of such cognitive problems would be speculative, however, even if mothers had been interviewed, because there is no definitive diagnostic test to determine the cause. As in any study using solely medical records, incomplete or inaccurate recording of data could have led to underreporting in records of both case and control mothers.

In conclusion, health care providers should routinely screen, promptly intervene, and refer for treatment all women of childbearing age who have problems associated with substance abuse, such as depression, sexual abuse, and injuries. Intervention becomes even more important for women who have had a child with FAS or some characteristics of FAS. Emergency departments and clinics should use standardized screening tools to assess such patients and should have protocols for referral to appropriate treatment facilities and for prenatal care. Prenatal care providers, especially, should use systematic screening for maternal alcohol use early in routine prenatal care and should work in concert with treatment programs geared toward pregnant women and their families. The IHS and Centers for Disease Control and Prevention have validated and approved a prenatal health assessment tool to screen for substance use in prenatal clinics. ${ }^{30-32}$ The latest version of this form and instructions for its use are available on-line at http://forms.psc.gov/ forms/IHS/ihs.html.

Health care providers should promote and assure ready access to effective family planning measures, especially for women who are unable to abstain from alcohol during pregnancy. More research and funding are urgently needed to determine which treatment modalities are most effective and to assure that appropriate treatment programs and facilities are readily available for substance abuse, mothers with special needs, such as cognitive mental illness, dysfunction, low educational level, pregnancy, dysfunctional families, and sole responsibility for child care. Greater efforts are needed to update physicians who provide emergency and prenatal care on effective methods for screening and counseling women for alcohol abuse. ${ }^{33}$

The authors gratefully acknowledge the record abstraction done by Angel Wilson, FNP; Mary Ewing, FNP; George Coy, MPH; Barbara Frost, MD; Betty Reppert, PA-C, MPH; Patricia Reams, MD, MPH; Dana Sleicher, MA, MPH; Patricia Maddox, MSN, MPH; Joan Kub, PhD; Juliette Raymond, MD, MPH; Barbara E. Parker, RN, MPH; Nancy Glass, MSN, MPH; Luis Callejas, MD, MPH; Elizabeth Jordan, RN, MSN; Nancy Deckert, RN; Deborah Kuehn, RN/CNP, MSN; L Russell Canfield, MD; and Katherine Canfield, MD. The authors also gratefully acknowledge the data entry done by Andrew Desruisseau, MD, John M. Marion, Laurie Pope, and Loralei Lacina, MD. Michele Strachan, MD, Don Blackman, PhD, Eva Marie Smith, MD, R. Louise Floyd, DSN, Diane Burkom, and the late Christopher Krogh, MD, made valuable contributions to the project. Edith Welty, MD, and Phil May, $\mathrm{PhD}$, provided editorial input.

\section{References}

1. Sokol RJ, Martier SS, Ager JW. The T-ACE questions: practical prenatal detection of risk-drinking. Am J Obstet Gynecol 1989;160:863-8.

2. Welty TK. The epidemiology of alcohol use and alcohol-related health problems among American Indians and Alaska Natives. In: Mail PD, HuertinRoberts S, Martin SE, Howard J, editors. Alcohol use among American Indians and Alaska Natives: multiple perspectives on a complex problem. Bethesda: National Institute on Alcohol Abuse and $\mathrm{Al}-$ coholism, 2003:49-70. (National Institute on Alcohol Abuse and Alcoholism Research monograph no. 37.)

3. Duimstra C, Johnson D, Kutsch C, et al. A fetal alcohol syndrome surveillance pilot project in American Indian communities in the Northern Plains. Public Health Rep 1993;108:225-9. 
4. Kvigne VL, Bad Heart Bull LB, Welty TK, Leonardson GR, Lacina L. Relationship of prenatal alcohol use with maternal and prenatal factors in American Indian women. Soc Biol 1998;45:214-22.

5. Use of international classification of diseases coding to identify fetal alcohol syndrome-Indian Health Service facilities, 1981-1992. MMWR Morb Mortal Wkly Rep 1995;44:253-5, 261.

6. Linking multiple data sources in fetal alcohol syndrome surveillance-Alaska. MMWR Morb Mortal Wkly Rep 1994;42:312-4.

7. SAS/STAT user's guide, release 6.03 edition. Cary, NC: SAS Institute Inc, 1988:1028.

8. Epi info, version 6. Atlanta: Centers for Disease Control and Prevention, 1994.

9. Stratton K, Howe C, Battaglia F, editors. Fetal alcohol syndrome. Washington DC: National Academy Press, 1996.

10. Viljoen D, Croxford J, Gossage JP, Kodituwakku PW, May PA. Characteristics of mothers of children with fetal alcohol syndrome in the Western Cape Province of South Africa: A case-control study. J. Alcohol Stud, in press 2002;63:6-17.

11. Abel EL. Fetal alcohol syndrome. Oradell, NJ: Medical Economics Books, 1990.

12. Egeland GM, Perham-Hester KA, Gessner BD, Ingle D, Berner JE, Middaugh JP. Fetal alcohol syndrome in Alaska, 1977 through 1992: an administrative prevalence derived from multiple data sources. Am J Public Health 1998;88:781-6.

13. Bagheri MM, Burd L, Martsolf JT, Klug MG. Fetal alcohol syndrome: maternal and neonatal characteristics. J Perinat Med 1998;26:263-9.

14. May PA, Hymbaugh KJ, Aase JM, Samet JM. Epidemiology of fetal alcohol syndrome among American Indians of the Southwest. Soc Biol 1983;30(4): 374-87.

15. Sociodemographic and behavioral characteristics associated with alcohol consumption during pregnancy-United States, 1988. MMWR Morb Mortal Wkly Rep 1995;44:261-4.

16. Beckman LJ. Treatment needs of women with alcohol problems. Alcohol Health Res World 1994;18: 206-11.

17. Wilsnack SC, Wilsnack RW, Hiller-Sturmhofel S. How women drink. Alcohol Health Res World 1994; 18:173-81.

18. Abel EL. An update on incidence of FAS: FAS is not an equal opportunity birth defect. Neurotoxicol Teratol 1995; 17:437-43.

19. Maier SE, Chen WJ, West JR. The effects of timing and duration of alcohol exposure on development of the fetal brain. In Abel EL, editor. Fetal alcohol syndrome. New York: CRC Press, 1996:27-50.

20. Manson SM, Shore JH, Baron AE, Ackerson L, Neligh G. Alcohol abuse and dependence among American Indians. In: Helzer JE, Canino G, editors. Alcoholism in North America, Europe, and Asia. New York: Oxford Press, 1992.

21. Bassuk EL, Melnick S, Browne A. Responding to the needs of low-income and homeless women who are survivors of family violence. J Am Med Womens Assoc 1998;53(2):57-64.

22. Gomberg ESL. Risk factors for drinking over a woman's life span. Alcohol Health Res World 1994; 18:220-7.

23. Lex BW. Alcohol and other drug abuse among women. Alcohol Health Res World 1994;18:212-9.

24. Holer HD, Saltz RF, Grube JW, Voas RB, Gruenewald PJ, Treno AJ. A community prevention trial to reduce alcohol-involved accidental injury and death: an overview. Addiction 1997;92(Suppl 2): S155-71.

25. Pernanen K. Alcohol in human violence. New York: Guilford Press, 1991.

26. Deal SR, Gavaler JS. Are women more susceptible than men to alcohol-induced cirrhosis? Alcohol Health Res World 1994;18:189-91.

27. Abel EL. Fetal alcohol syndrome in families. Neurotoxicol Teratol 1988;10:1-2.

28. Larimer ME, Palmer RS, Marlatt GA. Relapse prevention. Alcohol Health Res World 1999;23(2):15160.

29. Burd L, Shea TE, Knull HJ. "Montana gin": ingestion of commercial products containing denatured alcohol among Native Americans. Stud Alcohol 1987;48:388-9.

30. Gale TC, White JA, Welty TK. Differences in detection of alcohol use in a prenatal population (on a Northern Plains Indian reservation) using various methods of ascertainment. S D Med J 1998;51:23540.

31. Bad Heart Bull LB, Kvigne VL, Leonardson GL, Lacina L, Welty TK. Validation of a self-administered questionnaire for prenatal alcohol use in Northern Plains Indian women. Am J Prev Med 1999;16(3):240-3.

32. Li C, Olsen Y, Kvigne V, Welty T. Implementation of substance use screening in prenatal clinics. S D Med J 1999;52:59-64.

33. Diekman ST, Floyd RL, Decoufle P, Schulkin J, Ebrahim SH, Sokol RJ. A survey of obstetriciangynecologists on their patients' alcohol use during pregnancy. Obstet Gynecol 2000;95:756-63. 